\title{
Nitrate respirers mediate anaerobic As(III) oxidation in filters
}

\author{
C.Y. Jing \& J.L. Cui \\ Research Center for Eco-Environmental Sciences, Chinese Academy of Sciences, Beijing, P.R. China
}

\begin{abstract}
Microorganisms play a key role in the redox transformation of arsenic in aquifers. In this study, the impact of indigenous bacteria, especially the prevailing nitrate respirers, on arsenite oxidation was explored during groundwater filtration using granular $\mathrm{TiO}_{2}$ and subsequent spent $\mathrm{TiO}_{2}$ anaerobic landfill. X-ray absorption near edge structure spectroscopy analysis showed As(III) oxidation ( $46 \%$ in 10 days) in the presence of nitrate in the simulated anaerobic landfills. The Fe phase showed no change during the anaerobic incubation. Incubation experiments implied that the indigenous bacteria completely oxidized arsenite to arsenate in 10 days using nitrate as the terminal electron acceptor under anaerobic conditions. Phylogenetic tree analysis revealed that Proteobacteria was the dominant phylum, with Hydrogenophaga (34\%), Limnohabitans (16\%), and Simplicispira $(7 \%)$ as the major bacterial genera. The nitrate respirers especially from the Hydrogenophaga genus anaerobically oxidized As(III) using nitrate as an electron acceptor instead of oxygen. Our study implied that microbes can facilitate the groundwater As oxidation using nitrate on the adsorptive media.
\end{abstract}

\section{INTRODUCTION}

Various treatment technologies have been extensively studied during last decades to mitigate the severe problem of arsenic (As) tainted groundwater (Hu et al., 2015). As a consequence of enhanced As removal, a significant amount of As-bearing solid residuals is generated and disposed of in landfills, where As speciation and fate are generally determined by the ubiquitous microbes in the aquifer (Clancy et al., 2013).

A series of arsenite (As(III)) oxidizing bacteria have been successfully isolated and employed to transform As(III) to arsenate (As(V)) for As remediation, because $\mathrm{As}(\mathrm{V})$ is much more strongly adsorbed than $\mathrm{As}(\mathrm{III})$. Considering the ubiquitous existence of As(III) oxidizing bacteria in groundwater, we hypothesize that the indigenous As(III) oxidizing bacteria in groundwater should affect the speciation of adsorbed As in filters.

In the subsurface, As is often released into the groundwater coupled with a microbial-reductive process. Under such anoxic conditions, microorganisms critically influence As release using common oxyanions including sulfate and nitrate. High nitrate concentrations often restrain the release of As, which is attributed to the nitrate-dependent bacterial oxidation of As(III). A variety of bacterial isolates or communities can oxidize As(III) with nitrate as an electron acceptor under anaerobic conditions. However, the impact of indigenous nitrate respires in groundwater on As(III) oxidation in filters and subsequent landfill of the As-laden materials remains unclear. Considering high nitrate concentrations in groundwater (up to $25-198 \mathrm{mg} \mathrm{L}^{-1}$ ) due to agricultural activities, the effect of nitrate and indigenous nitrate respirers on As speciation in filters and landfills motivated our study.
The objective of this study was to investigate the role of indigenous bacteria and nitrate on the transformation of As during groundwater filtration and in landfills. The change in As and $\mathrm{Fe}$ speciation on the spent $\mathrm{GTiO}_{2}$ under anaerobic conditions was studied using X-ray absorption near edge structure (XANES) spectroscopy. The microbial diversity of the indigenous bacteria was characterized using 16S rRNA sequences. By combining XANES and 16S rRNA analysis, we intend to elucidate the effect of microbe and nitrate supplementation on As transformation. The result of our study will improve the understanding of the fate of As during filtration and anaerobic landfills.

\section{METHODS/EXPERIMENTAL}

\subsection{Filtration}

Field filtration experiments were conducted on site at Shanxi, China. Approximately $14.6 \mathrm{~g} \mathrm{GTiO}_{2}$ were loaded in a $1.2-\mathrm{cm}$ diameter column, resulting in a bed volume (BV) of $14.5 \mathrm{~mL}$. The empty bed contact time (EBCT) for the filter was $0.21 \mathrm{~min}$.

Three treatments of $\mathrm{GTiO}_{2}$ columns in duplicates were (1) GGW, (2) GGW amended with $10 \mathrm{mg} \mathrm{L}^{-1}$ nitrate, and (3) SGW. The influent and effluent were collected periodically, passed through a $0.22 \mu \mathrm{m} \mathrm{mem-}$ brane filter, and then preserved in the dark with 5\% $\mathrm{HCl}$ at $4{ }^{\circ} \mathrm{C}$ before analysis. At the end of a filtration cycle, the columns were stored on dry ice in a cooler in the field and transported to the lab for various analysis. The indigenous microorganisms were obtained by extracting the spent $\mathrm{GTiO}_{2}$. 


\subsection{Anaerobic incubation with indigenous microorganisms}

To study microbial As(III) oxidation, the indigenous microorganisms were mixed with SGW containing $1.8 \mathrm{mg} \mathrm{L}^{-1} \mathrm{As}(\mathrm{III})$ and $10.0 \mathrm{mg} \mathrm{L}^{-1}$ nitrate under anaerobic incubations (glovebox with $100 \% \mathrm{~N}_{2}$ ). For comparison, incubation was also performed with no addition of nitrate. To test the role of microbes, the particles extracted from the spent $\mathrm{GTiO}_{2}$ were autoclaved and added into the incubation experiment as a control study.

Bacterial DNA was extracted from the indigenous particles from the spent $\mathrm{GTiO}_{2}$ using a power soil DNA kit. Standard procedures were used for DNA amplification, ligation and cloning. DNA sequencing was performed by the TSINGKE Company (Beijing, China). Sequence alignments were performed using the Clustal X2 program with the sequences of the GenBank database. The sequence similarity was assessed using BLAST. Phylogenetic trees were generated with the neighbor-joining method using MEGA version 5.0.

\section{RESULTS AND DISCUSSION}

\subsection{Adsorption filtration}

The As(III) breakthrough point at $10 \mu \mathrm{g} \mathrm{\textrm {L } ^ { - 1 }}$ occurred earlier in GGW ( $\sim 600 \mathrm{BVs})$ than in SGW ( $2000 \mathrm{BVs})$. At this breakthrough point, the corresponding As adsorption was $0.40 \pm 0.04 \mathrm{mg}^{-\mathrm{As} \mathrm{g}^{-1}}$ $\mathrm{GTiO}_{2}$ in GGW and $1.34 \pm 0.07 \mathrm{mg} \mathrm{g}^{-1}$ in SGW. The lower As adsorption in GGW than in SGW may be attributed to strong competition from coexisting anions, viz. silicate and carbonate, at high concentrations. The addition of $10 \mathrm{mg} \mathrm{L}^{-1}$ nitrate to GGW did not inhibit the uptake of As, suggesting the stronger affinity of As to $\mathrm{TiO}_{2}$ as an inner-sphere surface complex compared with outer-sphere nitrate complex (Cui et al., 2018).

\subsection{Speciation and transformation of $\mathrm{As}$ and $\mathrm{Fe}$}

The speciation of the adsorbed As under anaerobic conditions was characterized using XANES. At the beginning of the anaerobic incubation after filtration experiment $(\mathrm{t}=0 \mathrm{~d}), \mathrm{As}(\mathrm{III})$ on spent $\mathrm{GTiO}_{2}$ for $\mathrm{SGW}$, $\mathrm{GGW}$, and $\mathrm{GGW}+\mathrm{NO}_{3}^{-}$were $87 \%, 71 \%$, and $71 \%$, respectively.

The Fe K-edge XANES analysis showed that the retained $\mathrm{Fe}$ on $\mathrm{GTiO}_{2}$ was dominated by amorphous ferric arsenate $\left(\mathrm{amFeAsO}_{4}\right)$ (67-69\%), ferrihydrite (24-26\%), and a small amount of goethite (5-8\%). An insignificant difference $(p<0.01, \mathrm{R}=0.932)$ of Fe species on the spent $\mathrm{GTiO}_{2}$ was found for GGW and $\mathrm{GGW}+\mathrm{NO}_{3}^{-}$. The Fe phase showed no change during the 10-d incubation under anaerobic conditions, suggesting that the oxidation of adsorbed As(III) was not related to $\mathrm{Fe}$.

\subsection{As(III) oxidation by indigenous microorganism}

To examine the hypothesis that indigenous microorganisms involved in As(III) oxidation under anaerobic condition, the retained particles on the surface of $\mathrm{GTiO}_{2}$ were collected and mixed with $1.8 \mathrm{mg} \mathrm{L}^{-1}$ As(III) in SGW. As(III) was not oxidized in SGW alone, sterilized SGW controls, or the control samples with nitrate amendment. In contrast, As(III) was completely oxidized to $\mathrm{As}(\mathrm{V})$ in the $\mathrm{SGW}$ amended with nitrate in $10 \mathrm{~d}$. The comparison results indicate that the microbes in GGW should facilitate As(III) oxidation in the presence of nitrate under anaerobic conditions, while chemical oxidation of As(III) can be neglected.

Microbial-assisted As(III) oxidation should play a major role in As transformation on spent $\mathrm{GTiO}_{2}$, particularly when nitrate is available. Phylogenetic tree analysis revealed that Proteobacteria was the dominant phylum, with Hydrogenophaga (34\%), Limnohabitans (16\%), and Simplicispira (7\%) as the major bacterial genera. The nitrate respirers especially from the Hydrogenophaga genus anaerobically oxidized As(III) using nitrate as an electron acceptor instead of oxygen.

\section{CONCLUSIONS}

The adsorbed As(III) in filters for tainted groundwater can be oxidized to $A s(V)$ in the presence of nitrate without oxygen. Nitrate absence during microbial incubation brought no redox change in As species. Microbial community analysis of the groundwater indicated Hydrogenophaga genus contributed to $34 \%$ of the total cloned sequences. Some indigenous bacteria belonging to Hydrogenophaga genus may anaerobically oxidize As(III) using nitrate as the electron acceptor. Our study highlighted that the presence of nitrate improves microbial As(III) oxidation in groundwater and facilitates in situ immobilization of As on spent adsorptive media under anaerobic conditions. Further isolation of such kinds of bacterial species is helpful to strengthen their role on As(III) oxidation and nitrate reduction, remediating both pollutants.

\section{ACKNOWLEDGEMENTS}

We acknowledge the financial support of the Strategic Priority Research Program of the Chinese Academy of Sciences (XDB14020201).

\section{REFERENCES}

Clancy, T.M., Hayes, K.F. \& Raskin, L. 2013. Arsenic waste management: A critical review of testing and disposal of arsenic-bearing solid wastes generated during arsenic removal from drinking water. Environ. Sci. Technol. 47: 10799-10812.

Cui, J., Du, J., Yu, S. \& Jing, C. 2018. Groundwater arsenic removal using granular $\mathrm{TiO}_{2}$ : integrated laboratory and field study. Environ. Sci. Pollut. Res. 22(11): 8224-8234.

$\mathrm{Hu}$, S., Shi, Q.T. \& Jing, C.Y. 2015. Groundwater arsenic adsorption on granular $\mathrm{TiO}_{2}$ : integrating atomic structure, filtration, and health impact. Environ. Sci. Technol. 49(16): 9707-9713. 